\title{
Information Technology in the Dissemination of Results of the Primary Health Care Evaluation in Brazil: A Qualitative Study
}

\author{
Osvaldo de Goes Bay Junior ( $\sim$ osvaldobay_jr@hotmail.com ) \\ Federal University of Rio Grande do Norte \\ Cícera Renata Diniz Vieira Silva \\ Federal University of Rio Grande do Norte \\ Cláudia dos Santos Martiniano \\ State University of Paraíba. Campina Grande \\ Lygia Maria de Figueiredo Melo \\ Federal University of Rio Grande do Norte \\ Marize Barros de Souza \\ Federal University of Rio Grande do Norte \\ Monique da Silva Lopes \\ Federal University of Rio Grande do Norte \\ Ardigleusa Alves Coelho \\ State University of Paraíba. Campina Grande \\ Paulo de Medeiros Rocha \\ Federal University of Rio Grande do Norte \\ Themis Xavier de Albuquerque Pinheiro \\ Federal University of Rio Grande do Norte \\ Nadja de Sá Pinto Dantas Rocha \\ Federal University of Rio Grande do Norte. Natal \\ Severina Alice da Costa Uchôa \\ Federal University of Rio Grande do Norte. Natal
}

Research Article

Keywords: Information Technology, Information Dissemination, Health evaluation, Primary Health Care, Open data, Data Visualization

Posted Date: September 7th, 2021

DOI: https://doi.org/10.21203/rs.3.rs-638947/v1

License: (c) (i) This work is licensed under a Creative Commons Attribution 4.0 International License. Read Full License 


\section{Abstract}

Background: Considering advancements in information technology for disseminating results of evaluations, it is essential to demonstrate the functionalities and performance of these practices in order to achieve the objectives established by the evaluation proponents. This study aimed to evaluate the use of information technology for disseminating results obtained from the Primary Health Care evaluation in Brazil.

Methods: A qualitative single-case study was performed with triangulation of techniques and key informants. Analyses of public documents and field research were conducted. Convenience sample of 54 participants (seven from the Department of Primary Care/Ministry of Health and 47 from teaching and research institutions) was selected from the external evaluation team. Content analysis was performed, and the Atlas ti.8.4.24 software organized, managed, and categorized textual data. Codification was performed by peers (three researchers) while experts validated codes (two researchers). Right after, codes were extracted and categorized.

Results: Dissemination of results is complex due to multiple components. Incorporation also favored advances in data observation and implementation of data openness, becoming available for professionals, policymakers, and universities. Challenges regarding delivery time of reports, access restriction, lack of interest, and digital skills influenced reaching expected goals of the proponent.

Conclusion: Information technology for disseminating results of evaluations may improve performance of health teams and managers and redefine priorities of work processes to strengthen Primary Health Care. Emphasis in planning, technological infrastructure, digital inclusion, and policy decision making is recommended to disseminate data effectively to the population.

\section{Background}

At the end of the evaluative process, there is a motivation to learn, understand, and share results among involved parties and society members [1]. Several evaluations collect valuable and informative data regarding their programs and services; however, proponents often do not share these results with stakeholders [2].

In this sense, dissemination of results is essential to conclude the evaluative process. The goal is to completely disclosure data through impartial and consistent reports [3]. Personnel responsible for the evaluation must ensure that all involved individuals and institutions fully access results [4].

Dissemination of results can make data, information, and knowledge available and usable by applying diverse channels (communication routes) and modalities (actual layout of communication). Its implementation requires adequate planning to achieve public policymakers, researchers, managers, professionals, or health system users [3] and may change policies, programs, or practices and social, financial, and political support [2].

Data are more accessible, readable, and free of restriction due to the development and use of Information Technology (IT), which helps collect and process information in different ways using digital tools $[5,6]$. However, this is not restricted to exposition since data infrastructure is being actively developed in healthcare to improve decision-making and allow the creation of products, services [5] and new methods for data visualization to fill gaps between producers and consumers of knowledge [7].

This reality can be observed in an extensive evaluation of Primary Health Care (PHC) in Brazil, namely External Evaluation of National Program for Access and Quality Improvement in Primary Care (AE/PMAQ-AB), which verified a set of patterns regarding access and quality. Some questions were used for team certification and information gathering to guide improvements in public health policy. The program had three evaluative cycles (2011/2012, 2013/2014, and 2015/2019) conducted by teaching and research institutions (IEPs) in Brazil. On the third cycle, 42,975 Primary Health Care Teams were evaluated in 5,570 Brazilian municipalities, and financial support was established according to performance [8-10].

AE/PMAQ-AB data were systematized and publicized to facilitate and optimize its use [10]. Transparency for disclosing results is also in the guideline of the program [12]. To attend to this demand, evaluators provided technological tools supported by IT, such as online disclosure of descriptive and analytical reports, the Portraits of Primary Health Care, and publication of microdata (i.e., data obtained in the lowest level of disaggregation) [8-10]. As a result, Brazil presents a large national data repository on PHC [13] used by policymakers, academic community, and government agencies [10, 11].

Currently, interest increased in the field of dissemination of results, specifically regarding data observation and use. Some authors claim this topic achieved a critical stage capable of influencing the evaluation experts to search for better strategies for communication projects [14-16]. For this, empirical research is needed to evaluate functionality and performance of these practices to reach expected goals established by proponents [16]

Despite research demand and the increased number of open data sources available in health [17], the way evaluation can use technology to open new channels for data disclosure by different stakeholders is considered underexplored. This study aimed to evaluate the use of information technology for disseminating results obtained from the Primary Health Care evaluation in Brazil.

\section{Method}

\section{Study design}

This study was conducted inside a larger research project investigating standard of quality of AE/PMAQ-AB. A qualitative single-case study was performed to evaluate IT use for disseminating results [18]. Triangulation of techniques and key informants were adopted to establish different analyses. 
Evaluation was intentionally chosen due to its innovative technological system for dissemination of results and protagonism in the National Program for Access and Quality Improvement in Primary Care (PMAQ-AB), whose objective is to induce the expansion of access and quality improvement in order to allow greater transparency and effectiveness of government actions directed to Primary Health Care. The PMAQ-AB has an extensive, complex and innovative payment system that considers the performance of primary health care teams [8].

\section{Population sample and study location}

Initially, we analyzed documents from the Brazilian Ministry of Health regarding dissemination of results. Public documents presenting methods for disseminating results and online platforms were included. Five documents were analyzed (Table 1).

Table 1: Document/finder, title, and document type used.

\section{DOCUMENT/ FINDER}

D1 http://189.28.128.100/dab/docs/portaldab/documentos/nota_metodologica_2_ed_ab_absb_certificacao.pdf

D2

http://189.28.128.100/dab/docs/portaldab/documentos/Manual_Instrutivo_3_Ciclo_PMAQ.pdf

\section{TITLE}

Methodological note of Primary Care team's certification

\section{TYPE}

DOCUMENT

Aim to present the applied methodology to certify teams that joined the third PMAQ-AB cycle.

Intuitive
manual for
Primary Care
and Family
Health Support
Teams

Teams

National Program for Access and Quality Improvement in Primary Care Analytical Reports

\section{Aim to present} the National Program for Access and Quality Improvement in Primary Care (PMAQ).

Online platform for analytical report, with information to support discussion of some evaluative aspects.

\section{D4}

https://retratos.navi.ifrn.edu.br/
Portraits of Primary Health Care

\section{This system aims to transform data from the third PMAQ-AB cycle into useful information for monitoring and managing primary care teams and managers. \\ Data obtained by AE/PMAQ- $A B$ in its lowest disaggregation}

External Evaluation Microdata level.

Source: Research collection, 2019.

Field research was conducted between July 2018 and December 2019 at the Department of Primary Care/Ministry of Health (DAB/MS) in Brasília and 06 IEPs that conducted the third AE/PMAQ-AB cycle. Convenience sample was composed of 54 participants ( 07 from DAB/MS and 47 from IEPs) from the team that conducted the third cycle.

\section{Instrument construction}

Item Matrix for evaluating the External Evaluation of Primary Health Care (https://doi.org/10.6084/m9.figshare.14676504.v5) was used to elaborate the instrument. This matrix presents validated items for meta-evaluative studies and adequation of theoretical basis guided by the Centers for Disease Control and Prevention and Joint Committee on Standards for Education Evaluation [20]. 
The item "Meeting stakeholder needs through the result dissemination method", representing the subdimension "Result dissemination" inserted in the dimension "Sharing Lessons Learned" was used. The following questions guided data collection: "In your opinion, were documents available (with results, analysis, and guidance) to those interested in the evaluation process?", "Did availability occur at an opportune time?", and "Did methods for disclosing results attend necessities and interests of those involved in the evaluative process?".

\section{Data collection procedures}

Seven semi-structured interviews were performed: one from the coordination of the General Commission for Monitoring and Evaluation of Primary Care from DAB/MS; and six from the general coordination of IEPs. The focal group followed Kitzinger [21] and was performed with one moderator and one rapporteur. Seven focal groups were conducted: one group with seven technicians from coordination of DAB/MS, and six groups with at least six researchers from AE/PMAQ-AB. Participants were informed about study objectives and voluntary participation before data collection. Informed consent form and voice recording authorization form were obtained from all participants [22].

Interviews and focal groups were recorded (audio) for approximately one hour. Few notes summarizing answers were taken. In the focal group, notes were taken by the moderator. Right after, all material was transcribed and transcripts were read and compared with original recording.

Interviews and focal groups were identified only with the first letter of the technique (I) or (FG), followed by sequence of data collection (e.g., 1, 2, n.). The evaluator was identified as I-DAB and FG-DAB.

\section{Data analysis}

Atlas ti.8.4.24 was used for organization, management, and categorization of textual data. Content analysis was conducted according to Bardin [23]. The software allowed codification of recorded units (categorization basis) and organization in groups by code, with possibility of elaborating analytical memos and registering comments regarding empirical data.

Peer reading strategy (group of three researchers) was adopted to select quotes (message segment-context unit) and their linking to a specific code. Transcriptions were carefully read in this step, and codification occurred after consensus (Table 2). Comments were noted, and analytic memos were constructed using experiences and references. This moment assured familiarity with corpus data and initial systematization of ideas to interpret quotes.

Table 2: Example of codification using quotes extracted from an interview.

\begin{tabular}{ll} 
GROUPS OF CODES & CODES (Record unit) \\
\hline $\begin{array}{l}\text { Dissemination of } \\
\text { results: Regarding } \\
\text { Reports }\end{array}$ & $\begin{array}{l}\text { Lack of investment as barrier to } \\
\text { disclosure results in opportune } \\
\text { time }\end{array}$ \\
\hline
\end{tabular}

\section{QUOTES (Context unit)}

Researcher: In your opinion, did availability of evaluation results occur at an opportune time?

Informant: without investments in technology, professionals, and teams, it is practically impossible to achieve our aims, i.e., disclose results at an opportune time to fundament decisions.

Researcher: Regarding the method of disclosing results, do you think the needs of interested parties were attended?

Dissemination of Difficulty of teams to access results: Regarding and interpret reports

Informant: the feeling I have when I see the team and difficulties to information access (...) many information is not accessed. Results are important.

Reports

Source: Research collection, 2019.

Specific reports were elaborated for each code group using the software and submitted to experts (two researchers) to validate relations between quotes and codes (recoding could occur whenever needed). In the following step, corpus encoding was concluded to allow interpretation and inference [23].

After these steps, we separated all codes of the item "Meeting stakeholder needs through the result dissemination method" from subdimension "Result dissemination". Therefore, the material was analyzed and organized in four thematic categories: IT use to disseminate AE/PMAQ-AB results; online reports in information disclosure process; Portraits of Primary Health Care as open data strategy; and database access in a virtual environment.

\section{Ethical approval}

This study was approved by the research ethics committee of the Onofre Lopes University Hospital/Federal University of Rio Grande do Norte (CAEE: 84537418.1.0000.5292) and followed the resolutions of the Brazilian National Commission for Ethics in Research (CONEP). All participants signed the Free and Informed Consent and/or the Consent Term.

\section{Results}

Quotes of informants illustrate thematic categories. Omitted words or sentences are indicated by ellipsis in brackets [...].

\section{Information Technology use to disseminate AE/PMAQ-AB results}


Technology was essential to disseminate results, especially for information transparency and ease of its use, as highlighted below:

[...] data systematization and publicity obtained clearly and objectively during the third cycle to facilitate and optimize use of data. From this perspective, the goal is always to move forward, seeking new consulting tools for the produced information. [...] systems, microdata, individualized reports per state, municipality, and team can be performed by accessing the e-Gestor and DAB/MS portal (D1).

According to the interviewer, despite the mechanism of dissemination of results, advancements regarding accessibility are needed due to difficulty in using the produced information.

[...] we need advances in methods even more accessible for managers and health workers, for permanent use of results in action plans to improve what is being performed (12).

Despite the use of technology, dissemination of results to interested parties at an opportune time is still challenging due to difficulties regarding investment, reduced technical team, and large number of variables in the instrument, according to DAB/MS:

We are trying to solve problems that hinder availability of results at an opportune time. Investments in technology and professionals are difficult. We lack a stronger IT development group to make these data available; lack of sufficient technical team; the instrument has many variables, making its validation difficult (FG-DAB).

\section{Online reports in information disclosure process}

The main purpose of reports was data and information sharing, mainly for managers and their teams, to contribute to action plans for PHC. According to the quote below, reports are available in a system developed by the demandant.

It is possible to access analytical and descriptive reports in the e-Gestor system, an important tool offered by the Ministry of Health for workers and managers to reflect some evaluated aspects of PMAQ. [...] promoting its use in local and municipal planning and resetting processes regarding work of teams and management to strengthen PHC (D2).

Technology use enabled availability of analytical reports to public access. These reports show data analysis from AE/PMAQ-AB and some recommendations to improve team performance.

Analytical reports are public documents available at the Primary Care Department/PMAQ/e-Gestor that consist of external evaluation analysis and suggestions to improve team performance (D3).

The main objective of this report is to provide analytical elements to support discussion and reflection of results and improve important services.

[...] to support primary care managers and teams in reflecting their work process and organization of health service access, from welcoming to spontaneous demand and team schedules. [...] may support discussion and reflection to improve these services (D3).

For DAB/MS, these reports present accessible data organization and availability, with pleasant navigability for interested parties.

[...] Janalytical reports have more pleasant interface and navigability, all with public access; any person can have access. [...] This improvement is attributed to qualification of the instrument and data, not to mention that tablets are better programmed (FG-DAB).

Despite the effort to structure reports with interface of easy access, managers and health teams still experience difficulties:

[...] analytical reports are great; the problem is that people cannot read information contained in the reports. Therefore, we have a problem because the municipality takes that report and does not know what to do with it [...] (I5).

Only managers have access to descriptive reports, and authentication with login and password is needed for information regarding PMAQ-AB team certification. Results show the possibility to follow team performance.

Descriptive reports are public access documents available at the portal of Primary Care Department/PMAQ/e-Gestor that contains PMAQ results by team, municipality, and state. Indexes are presented and compared in these reports, and teams receive certification in the first and second cycles of the program (in previous cycles) (D2).

Limited access of the manager to descriptive reports was mentioned as limitation to dissemination of results since information was restricted and used according to interest of the manager. DAB/MS considers data openness could increase usage:

Descriptive reports are under login and password of the manager, which is less interested in discussing these results. Maybe with public access, direct access without bureaucracy for teams, use of reports would have been greater (FG-DAB).

DAB/MS considers that methods for disclosing results are preliminary; however, it recognizes efforts to improve reports and contribute with its use by managers and teams. 
[...] I think our methods for disclosing results are still very preliminary; we have few reports, we improve in each cycle, but we are far from offering reports to contribute with use of results by manager and team workers for practical changes [...] (I-DAB).

\section{Portraits of Primary Health Care as open data strategy}

Portraits of Primary Health Care are considered another channel to disseminate results, compiling public results from all variables of AE/PMAQ-AB:

[...]Portraits of Primary Health Care is a collection of questions, a panorama that anyone can access. [...] to use information that makes sense. From this point of view, I think that DAB/MS favored dissemination of results (FG6).

AE/PMAQ-AB data in the Portraits of Primary Health Care platform is stored, available, and disclosed for all national territories.

Primary care portrayal provides information of more than 42,000 health teams of 5,324 municipalities of the third PMAQ-AB cycle. Data from 13,775 Family Health teams, 25,090 Family Health teams with Oral Health, 4,110 Expanded Centers of Family Health and Primary Care, and 30,346 Family Health Unities are available (D4).

Main resources available from Portraits of Primary Health Care provide data utility and produce information to be used by interested parties.

Appropriation of results of the third PMAQ-AB cycle and use and transformation of data into useful information in both primary care monitoring and management processes for teams and managers are one of the main goals of the proposed system (D4).

Organization for data access is performed by different methods, depending on objectives of interested parties.

Data can be accessed in four ways: by thematic, which provides variables grouped by theme and it is possible to reach the lowest level of disaggregation that are questions from the questionnaire; access by variables that compose the questionnaire; certification access, which provides information regarding performance of evaluated teams; and the last access is crossing variables, which crosses data from PMAQ external evaluation (D4).

As described above, thematic access allows simplified navigation of the instrument; access using variables can be performed individually or together by crossing variables of the instrument. Performance of evaluated teams can be verified using certification access.

\section{Database access in virtual environment}

Public access to AE/PMAQ-AB microdata (database) (Ministry of Health website) was another channel used for disseminating results. The virtual environment to access microdata comprises six modules, and data sheets related to each module can be downloaded according to geographic area (Brazil, State, and City). This sheet contains evaluated data and a dictionary to explain terms and codifications used for results (D5).

Despite the concern about data organization and availability, work with dataset is complex and may hinder the production of information for knowledge use:

[...] it is complex to transform those data into information. [...] I think that translation those data in a way that people can use in practice is challenging (I7).

Moreover, DAB/MS reaffirms the difficulty in using and understanding the available microdata.

[...] I question if our way of providing data facilitates its use and understanding. Microdata is difficult to use. We know that managers do not use all data, and we have not facilitated this use (FG-DAB).

\section{Discussion}

This study evaluated IT for disseminating AE/PMAQ-AB results. Technology use in evaluation allowed the development of different disclosure channels and methods for data observation, making results available, accessible, and interactive for interested parties.

However, after analyzing speeches, reports did not reach proposed goals due to delayed disclosure, probably because of lack of interest by managers and teams. Restricted access to descriptive reports and difficulty in understanding microdata were considered limitations for using reports. Most of these challenges may be overcome with adequate planning for disseminating results. To ensure greater accessibility, the plan must be designed in the early stage of evaluation and continued regardless of results [24].

According to the literature, online platform makes evaluation results more available for professionals and policymakers and establish connections between academic and evaluation fields [25]. This context offers an opportunity to participate, explore, reflect, generate knowledge, and increase comprehension of the evaluative process [14]. However, disclosure of results must be performed carefully to avoid overestimating practical effects of data observation using technological platform [16].

Analytical reports from AE/PMAQ-AB present pleasant navigability. Results are available by different methods (e.g., infographics, graphics, tables, and textual elements) and provide information to a larger public. Information from reports must be precise, reliable [26, 27], adjusted for the interested group, and provide information regarding who performed the evaluation and relevant discoveries to allow individuals to produce their judgments [28]. 
Adjustment of reports in the evaluation field is essential to interested individuals since dissemination of results is one of the main standards of quality. Efforts to make data interpretable are needed; otherwise, the reader would need assistance to interpret and comprehend information [15]. Currently, technology made visual resources more accessible for evaluators, who should consider capacitation to reduce frustration and misinterpretation [14].

Regarding learning process and elaboration of knowledge, the combination of visual and verbal explanation may increase comprehension and interest $[14 ; 16]$. Although reports are being published online to ensure accessibility for general public, researchers, managers, and professionals, evaluators must ensure that collected data provide intense dialogues with community or health service users, stimulating their participation in decisive processes.

Microdata is another channel used to disseminate results, in which demandant of AE/PMAQ-AB opt to make database publicly available for access, download, analysis, and knowledge generation. However, it is not known whether this method facilitates understanding or use by municipal managers. Although technology use enhances extensive data collection and storage that can be shared using servers or cloud platforms [27], capacity of analysis is low $[14 ; 27]$. Nevertheless, the way government manages raw data is criticized because availability must be collaborative to build shared knowledge spaces [5].

Portraits of Primary Health Care completes the mechanisms for disseminating AE/PAMQ-AB results. This system allows users to transform large data sets into smaller subsets to produce useful information that was previously difficult without this interactive tool. This tendency remains inserted in the main purposes of data observation since it increases comprehension and participation in the evaluative process [14].

Guided by data openness concept and considering a large amount of information, data observation allowed individuals to interact directly with results. This reality may be associated with development of technological tools and internet access, stimulating evaluators to publicly share data and become information consumers $[14 ; 25]$. The mechanism used by AE/PMAQ-AB to disseminate results demands digital knowledge and skills beyond evaluative practices. This continuous development of data observation and interaction and advances regarding data openness may become common in the evaluation field and reorganize evaluative practices [29].

Efforts of AE/PMAQ-AB proponents are observed to implement open data to promote transparency, use, and involvement of main policymakers, government agencies, and academic community. Moreover, productive partnerships between government and population may solve public problems and social changes. Data are considered source of power, and its opening is a strategy to redistribute power [6].

Therefore, it is necessary to progress from simple knowledge dissemination to action for effective use of data in decision-making; otherwise, this dissemination will be characterized only as information transparency [17; 30]. Regarding evaluation in the health field, the use of technological resources to disseminate results may favor social participation due to the possibility of amplifying different narratives and allowing insertion of the population in public management. Participation of the population and dialog between governments and citizens may occur according to open data management [31]. As indicated, more accessible tools and active interventions for Knowledge translation are needed to eliminate possible gaps and, enable its use in practice and decision-making.

Although this study presents different data sources, speeches from municipal managers, health teams, and developers of the technology used by AE/PMAQ-AB were unavailable and may be considered a limitation. Moreover, results cannot be generalized since this is a case study.

\section{Conclusion}

IT use was effective for dissemination of results. We observed a potential distribution of knowledge access due to extensive evaluation conducted in a short period among cycles and in a large territorial extension with regional disparities and high number of municipalities. However, managers lacked appropriation of knowledge produced by AE/PMAQ-AB due to possible overestimation of practical effects of technology.

Evaluators must provide a larger interval among evaluative cycles to sensitize PHC managers regarding obtained data and reduce gaps between data dissemination, use, and transformation into useful information to support discussions, reflections, and service improvements. Investments in technological infrastructure are essential, including expansion of digital inclusion. Political directions are needed to effectively deliver data to the population and improve PHC access and quality. We recommend focusing on difficulties of using produced knowledge from evaluations to strengthen health policies.

\section{Abbreviations}

IT: Information Technology

PHC: Primary Health Care

AE/PMAQ-AB: External Evaluation of National Program for Access and Quality Improvement in Primary Care

IEPs: teaching and research institutions in Brazil

PMAQ-AB: National Program to Improve Primary Care Access and Quality

DAB/MS: Department of Primary Care/Ministry of Health's 
I: Interviews

FG: Focal Groups

I-DAB: Evaluation Proponent Interview (Department of Primary Care/Ministry of Health)

FG-DAB: Evaluation Proponent Focal Group (Department of Primary Care/Ministry of Health)

CONEP: Comissão Nacional de Ética em Pesquisa (Brazilian National Commission for Ethics in Research)

\section{Declarations}

\section{Ethics approval and consent to participate}

Approved by research ethics committee of Onofre Lopes University Hospital - Federal University of Rio Grande do Norte (CAAE: 84537418.1.0000.5292) and followed the resolutions of the Brazilian National Commission for Ethics in Research (CONEP). All participants signed the Free and Informed Consent and/or the Consent Term.

\section{Consent for publication}

Not applicable.

\section{Availability of data and materials}

The datasets generated during and/or analyzed during the current study are not publicly available due to the privacy of personal information essential to link the databases but are available from the corresponding author on reasonable request.

\section{Competing interests}

All other authors declare they have no conflict of interest.

\section{Funding}

The study received partially financed from the North-Rio-Grandense Research and Culture Foundation (FUNPEC)/ Federal University of Rio Grande do Norte (UFRN) [grant number 5007.21.1415] and from National Council for Scientific and Technological Development (CNPq) [grant number 306024/20187]. The funders had no role in study design, data collection and analysis, decision to publish, or preparation of the manuscript.

\section{Authors' contributions}

All authors contributed to the study conception, design and development. OGBJ, TXAP, AAC, NSPDR, MSL and MBS collected the data, provided input into the analyses and interpretation. Material preparation was performed by OGBJ and MSL. The first draft of the manuscript was written by OGBJ, CRDVS, CSM and LMFM and all authors commented on previous versions of the manuscript. OGBJ, SACU, PMR, CRDVS, LMFM, and CSM conducted the study, supervised all aspects of its conduction. All authors read and approved the final version of the manuscript, and OGBJ had the final responsibility to submit the paper.

\section{Acknowledgements}

The authors would like to acknowledge colleagues at the Federal University of Rio Grande do Norte, Collective Health Department, who made important contributions to the work. We would like to express our sincere thanks to all four stakeholders in this study for their willingness to share their experiences.

The authors thank Probatus Academic Services for providing scientific language translation, revision, and editing.

\section{References}

1. Centers for Disease Control and Prevention et al. Preparing an Evaluation Report. Evaluation Briefs, № 11, 2018. Available from: https://www.cdc.gov/healthyyouth/evaluation/pdf/brief11.pdf

2. Centers for Disease Control and Prevention et al. Disseminating Program Achievements and Evaluation Findings to Garner Support Preparing an Evaluation Report. Evaluation Briefs, Nº9, 2018. Available from: https://www.cdc.gov/healthyyouth/evaluation/pdf/brief9.pdf

3. Centers for Disease Control and Prevention. Introduction to Program Evaluation for Public Health Programs: A Self-Study Guide. 2011. Available from: http://www.cdc.gov/eval/guide/index.htm.ã

4. Figueiró AC, Thuler LC, Dias ALF. Padrões internacionais dos estudos de linha de base. In: Hartz ZMA, Felisberto E, Silva LMV (Org.). Meta-avaliação da atenção básica à saúde: teoria e prática. Rio de Janeiro: Ed. Fiocruz; 2008. pp. 49-70.

5. Dodds L, Wells, P. Data infrastructure. In: Davies T, Walker, SB, Rubinstein, M, Perini, F (Eds.). The state of open data: Histories and horizons. Cape Town and Ottawa: African Minds and International Development Research Centre; 2019. pp. 260-273. D0I: 10.5281/zenodo.2668475. 
6. Davies T, Walker S, Rubinstein M, Perini, F (Eds.). The State of Open Data: Histories and Horizons. Cape Town and Ottawa: African Minds and International Development Research Centre; 2019. pp. 1-10. DOI: 10.5281/zenodo.2668475.

7. Otten JJ, Cheng K, Drewnowski A. Infographics and public policy: using data visualization to convey complex information. Health Affairs, 34(11), 1901-1907. https://doi.org/10.1377/hlthaff.2015.0642

8. Brasil. Ministério da Saúde. Secretaria de Atenção à Saúde. Departamento de Atenção Básica. Programa Nacional de Melhoria do Acesso e da Qualidade da Atenção Básica (PMAQ) Manual Instrutivo $3^{\circ}$ Ciclo (2015-2016). Brasília: Ministério da Saúde. 2017. Available from: http://189.28.128.100/dab/docs/portaldab/documentos/manual_de_campo_pmaq_3ciclo.pdf

9. Brasil. Ministério da Saúde. Portaria GM/MS nº 874 de 10 de maio de 2019. Brasília, DF: MS; 2018. Available from: https://www.in.gov.br/en/web/dou/-/portaria-n\%C2\%BA-874-de-10-de-maio-de-2019-108883717

10. Brasil. Ministério da Saúde. Nota Metodológica da Certificação das Equipes de Atenção Básica/ Programa Nacional de Melhoria do Acesso e da Qualidade da Atenção Básica (PMAQ-AB) - Terceiro ciclo. Brasília: Ministério da Saúde. 2018. Available from: http://189.28.128.100/dab/docs/portaldab/documentos/nota_metodologica_2_ed_ab_absb_certificacao.pdf

11. Saddi FC, Peckham S. Brazilian Payment for Performance (PMAQ) Seen From a Global Health and Public Policy Perspective: What Does It Mean for Research and Policy?. J Ambul Care Manage. 2018;41(1):25-33. doi:10.1097/JAC.0000000000000220

12. Brasil. Ministério da Saúde. Portaria GM/MS nº 1645 de 02 de outubro de 2015. Brasília: Ministério da Saúde. 2015. Available from: https://bvsms.saude.gov.br/bvs/saudelegis/gm/2015/prt1645_01_10_2015.html

13. Santos TCD, et al. PMAQ-AB e os pactos do SUS: função dispositivo ou repetição. In: Gomes LB, Barbosa MG, Ferla AA (Org.). Atenção básica: olhares a partir do programa nacional de melhoria do acesso e da qualidade-(PMAQ-AB). 1. ed. Porto Alegre: Rede Unida, 2016. p. 75-99. DOI: $10.18310 / 9788566659610$

14. Azzam T, Evergreen S, Germuth AA, Kistler, SJ. Data visualization and evaluation. New Directions for Evaluation, 2013 (139). p. 7-32. DOI: https://doi.org/10.1002/ev.20065

15. Evergreen S, Metzner C. Design principles for data visualization in evaluation. New directions for evaluation, 2013(140). p. 5-20. DOI: https://doi.org/10.1002/ev.20071

16. Mason S, Azzam T. In Need of an Attitude Adjustment? The Role of Data Visualization in Attitude Change and Evaluation Influence. American Journal of Evaluation. 2019;40(2):249-267. DOI:10.1177/1098214018778808

17. Irura M. Open data and health. In T. Davies, S. Walker, M. Rubinstein, \& F. Perini (Eds.), The state of open data: Histories and horizons. Cape Town and Ottawa: African Minds and International Development Research Centre. 2019. pp.166-180. DOI: DOI: 10.5281/zenodo.2668475.

18. Yin RK. Estudo de caso: planejamento e métodos. 3. ed. Trad. Daniel Grassi. Porto Alegre: Bookman, 2005.

19. Leonardi PM. Theoretical foundations for the study of sociomateriality. Information and organization.2013; 23(2), 59-76. DOI: https://doi.org/10.1016/j.infoandorg.2013.02.002

20. Uchoa SAC, et al. Item Matrix for Evaluating the External Evaluation of Primary Health Care.docx. figshare. 2021. Dataset. https://doi.org/10.6084/m9.figshare.14676504.v5

21. Kitzinger J. Grupos focais. In: Pope C, Mays N. Pesquisa qualitativa na Atenção à Saúde. 3. ed. Porto Alegre: Artmed, 2009. p.33-43.

22. Brasil. Ministério da Saúde. Conselho Nacional de Saúde. Resolução n. 466, de 12 de dezembro de 2012. Aprova diretrizes e normas regulamentadoras de pesquisas envolvendo seres humanos. Brasília, Diário Oficial da União, 12 dez. 2012.

23. Bardin L. Análise de conteúdo. São Paulo: Edições 70, 2011, 229p.

24. Howell EM, Yemane A. An Assessment of Evaluation Designs: Case Studies of 12 Large Federal Evaluations. American Journal of Evaluation. 2006;27(2):219-236. doi:10.1177/1098214006287557

25. Raftree L, Bamberger M. Emerging Opportunities: Monitoring and Evaluation in a Tech-Enabled World. The Rockerfeller Foundation. 2014. Available from: https://www.rockefellerfoundation.org/wp-content/uploads/Monitoring-and-Evaluation-in-a-Tech-Enabled-World.pdf

26. Centers for Disease Control and Prevention et al. Using Graphs and Charts to Illustrate. Evaluation Briefs, No 12, 2018. Available from: https://www.cdc.gov/healthyyouth/evaluation/pdf/brief12.pdf

27. Corlazzoli V, King Wale M, Nowak M, Parsons, J. ICTs for Monitoring \& Evaluation of Peacebuilding Programmes. UK Department for International Development.2014. Available from: http://www.sfcg.org/wp-content/uploads/2014/05/CCVRI-SSP-_ICT-and-ME-_Final.pdf

28. Jacobson MR, Azzam T. The effects of stakeholder involvement on perceptions of an evaluation's credibility. Eval Program Plann. 2018; 68:64-73. doi:10.1016/j.evalprogplan.2018.02.006

29. Jamieson V, Azzam T. The Use of Technology in Evaluation Practice. Journal Of MultiDisciplinary Evaluation. 2012. 8(18): 1-15. Available from: https://journals.sfu.ca/jmde/index.php/jmde_1/article/view/340

30. Straus SE, Tetroe JM, Graham ID. Knowledge translation is the use of knowledge in health care decision making. J Clin Epidemiol. 2011;64(1):6-10. doi:10.1016/j.jclinepi.2009.08.016

31. Open Data Charter. Principles: International Open Data Charter. 2015. Available from: https://opendatacharter.net/wpcontent/uploads/2015/10/opendatacharter-charter_F.pdf 